09,03

\title{
O природе близкраевого излучения ZnO при комнатной температуре
}

\author{
(С) И.Х. Акопян, М.Э. Лабзовскаяґ Б.В. Новиков, А.Ю. Серов, Н.Г. Философов, Н.Р. Григорьева \\ Санкт-Петербургский государственный университет, \\ Санкт-Петербург, Россия \\ ^E-mail: xrul@mail.ru
}

Поступила в Редакцию июля 2020 г.

В окончательной редакции июля 2020 г.

Принята к публикации июля 2020 г.

\begin{abstract}
Изучена экситонная фотолюминесценция оксида цинка в температурном интервале 5-300 К. Проведен анализ формирования контура полосы экситонного излучения при $300 \mathrm{~K}$ и возбуждении Не-Сd-лазером в спектрах нелегированных кристаллов, порошка марки ОСЧ и тонких ALD-пленок толщиной 4-450 nm.

Исследовано влияние процессов фотодесорбции и фотоадсорбции атмосферного кислорода на спектр экситонного излучения порошка $\mathrm{ZnO}$ в последовательных циклах смены среды вакуум-воздух при комнатной температуре и непрерывном возбуждении Не-Сd-лазером.
\end{abstract}

Ключевые слова: экситонное излучение, фотоадсорбция, фотодесорбция, экситон-фононное взаимодействие.

DOI: 10.21883/FTT.2020.11.50104.146

\section{1. Введение}

Оксид цинка, многие годы являясь модельным объектом при исследовании экситонных, экситонно-примесных и экситонно-дефектных состояний, в настоящее время благодаря высокой энергии связи экситона представляет интерес как перспективный материал для ряда оптических устройств (фотодиодов, фотокатализаторов, солнечных батарей, газовых и биологических сенсоров и др.), работающих при комнатной температуре [1]. Как известно, при комнатной температуре спектр экситонного излучения проявляется как одна широкая полоса, часто асимметричная. По литературным данным максимум экситонной полосы может смещаться в диапазоне $376-385 \mathrm{~nm}$, что авторы [2] связывают с влиянием примеси.

В настоящей работе исследуется экситонная фотолюминесценция (ФЛ) $\mathrm{ZnO}$ при комнатной температуре, анализируются спектральное положение максимума полосы, ее форма и полуширина в различных образцах $\mathrm{ZnO}$ (монокристаллы, нанокристаллические порошки, тонкие ALD-пленки).

Экситонная фотолюминесценция исследуется также в процессе десорбции и адсорбции атмосферного кислорода. Ранее нами было показано [3], что в формировании экситонной ФЛ ZnO важную роль играют адсорбированные на поверхности газы.

\section{2. Методика}

Исследования ФЛ проводились в гелиевом криостате замкнутого цикла Janis Research. При комнатной температуре образцы находились либо при атмосферном давлении, либо в вакууме при давлении $2 \cdot 10^{-4}$ Torr. Возбуждение ФЛ осуществлялось $\mathrm{He}-\mathrm{Cd}(\lambda=325 \mathrm{~nm}$,
$W=10 \mathrm{~mW}$ )-лазером. В качестве образцов использовались нелегированные монокристаллы, пленки, полученные методом ALD, толщиной от 4 до $450 \mathrm{~nm}$ на $\mathrm{Si}$-подложке, и порошки марки ОСЧ, состоящие из агломератов гексагональных нанокристаллитов размерами $20-500 \mathrm{~nm}$.

\section{3. Результаты и обсуждение}

I. Были изучены спектры ФЛ $\mathrm{ZnO}$ в интервале температур 5-300 К. При гелиевой температуре и возбуждении Не-Сd-лазером спектры близкраевой люминесценции (БКЛ) указанных выше типов образцов содержат линии связанных на мелких нейтральных и ионизованных донорах экситонов, в области коротких волн от которых может наблюдаться полоса свободного экситона, и в длинноволновой области, как правило, полоса с максимумом излучения при $374.5 \mathrm{~nm}$ (полоса А). В литературе в большинстве работ эту полосу связывают с излучением при переходе электрон зоны проводимости - акцептор [4]. При гелиевых температурах полосы экситон-фононных повторений или отсутствуют, или очень слабы.

На рис. 1 показаны спектры ФЛ в диапазоне температур от 5 до $300 \mathrm{~K}$ нелегированного монокристалла $(a)$, порошка $(c)$, пленки толщиной $4 \mathrm{~nm}(b)$ и пленки толщиной $450 \mathrm{~nm}(d)$.

Видно, что СФЛ образцов при $5 \mathrm{~K}$ сильно отличаются относительной интенсивностью излучения экситонных полос и полосы А. В спектре кристалла (рис. 1, $a$ ) полоса А отсутствует, в СЛ порошка (рис. 1,c) она сравнима по интенсивности излучения с излучением связанных экситонов. Вид CФЛ ALD-пленок зависит от их толщины. В спектрах пленок толщиной 4 и $10 \mathrm{~nm}$ 
полоса А много слабее экситонных линий (рис. $1, b$ ). В толстых пленках (более $100 \mathrm{~nm}$ ) дефектная полоса может стать доминирующей структурой в спектре (рис. $1, d)$. Кроме того, видна прямая корреляция между интенсивностью дефектной полосы и присутствием и интенсивностью полосы излучения первого фононного повторения экситона $(\mid=377.7 \mathrm{~nm})$. Как известно [5], в СЛ чистых кристаллов в силу требования закона сохранения квазиимпульса излучательные переходы с рождением одного LO-фонона при $T=5 \mathrm{~K}$ запрещены. Присутствие дефектов позволяет наблюдение таких переходов и при больших концентрациях первое фононное повторение может превосходить второе.

Проведено исследование формирования контура полосы экситонного излучения при повышении температуры от 5 до $300 \mathrm{~K}$ в образцах, низкотемпературные СФЛ которых сильно различаются соотношением интенсивностей экситонных и дефектной полос (рис. 1). Видно, что в СФЛ монокристалла (рис. 1, $a$ ), в котором дефектная полоса отсутствует, при повышении температуры одновременно с гашением линий связанных экситонов появляются и увеличиваются в интенсивности свободный экситон и его первое и второе фононные повторения. К $T=150 \mathrm{~K}$ в спектре БКЛ наблюдаются только излучение свободного экситона и его фононные реплики. При $T=300 \mathrm{~K}$ спектр ФЛ представляет собой широкую почти симметричную полосу, в которой трудно выделить фононную составляющую, с максимумом при $377 \mathrm{~nm}$ и полушириной $\sim 83 \mathrm{meV}$.

Температурная эволюция СФЛ-пленки толщиной $4 \mathrm{~nm}$, в спектре которой при $5 \mathrm{~K}$ полоса А много слабее экситонных структур, показана на рис. $1, b$. Полоса А перестает наблюдаться в СЛ после $200 \mathrm{~K}$. При $300 \mathrm{~K}$ спектр мало отличается от спектра монокристалла и состоит из одной полосы с максимумом $376.5 \mathrm{~nm}$ и полушириной $\sim 86 \mathrm{meV}$.

В СЛ порошка (рис. 1,c) хорошо выражена экситонфононная структура - первое, второе и третье фононные повторения при $5 \mathrm{~K}$ и при повышении температуры до $155 \mathrm{~K}$ - первое и второе. При $214 \mathrm{~K}$ спектр состоит из асимметричной полосы, коротковолновый край которой образуется неразрешенными полосами излучения свободного экситона и полосы А, а длинноволновый полосой второго фононного повторения экситона. При $T=300 \mathrm{~K}$ спектр представляет асимметричную полосу излучения (полуширина $\sim 143.7 \mathrm{meV}$ ) с максимумом в области первого фононного повторения экситона - 382 $\mathrm{nm}$ [7]. На длинноволновом краю отчетливо видна особенность при энергии второго фононного повторения, на коротковолновом - слабая особенность при энергии излучения экситона.

Спектр излучения толстой $450 \mathrm{~nm}$ пленки при $T=5 \mathrm{~K}$ содержит (рис. $1, d$ ) слабую полосу излучения свободного и связанных экситонов, интенсивную полосу А и полосу с максимумом $\sim 378 \mathrm{~nm}$, спектральное положение которой дает основание приписать еe LO-фононному повторению экситона. При повышении температуры полосы излучения дефектной полосы и экситон-фононного излучения смещаются, уширяются, при это меняется их относительная интенсивность в пользу экситон-фононной полосы. При $T=210 \mathrm{~K}$ полоса А еще отчетливо видна, далее до $270 \mathrm{~K}$ она присутствует в спектре как особенность на коротковолновом крыле контура излучения, при $T>270 \mathrm{~K}$ она не наблюдается. Заметим, что в $\mathrm{N}$-легированных MBI-пленках $\mathrm{ZnO}$ р-типа на сапфире переходы электрон зоны проводимости - акцептор наблюдаются до $T=213 \mathrm{~K}$ - температуры, при которой $N$ - акцептор термически ионизуется [6]. Спектр излучения пленки при $300 \mathrm{~K}$ имеет ярко выраженную асимметричную форму с максимумом при $385 \mathrm{~nm}$ и особенностью на коротковолновом хвосте в области $376 \mathrm{~nm}$ (полуширина полосы $\sim 156 \mathrm{meV}$ ).

Из приведенных выше результатов следует, что положение максимума полосы экситонного излучения $\mathrm{ZnO}$ и форма полосы при комнатной температуре определяются зависящими от степени дефектности разными вкладами экситонного, экситон-фононного и примесного излучений. В исследованных в настоящей работе типах образцов положение максимума экситонной полосы меняется в диапазоне от 376 до $385 \mathrm{~nm}$.

II. В работе продолжены исследования влияния среды на спектр близкраевого излучения порошка $\mathrm{ZnO}$ при RT и непрерывном возбуждении Не-Сd-лазером. B [3] было показано, что при вакуумировании образца интенсивность экситонной люминесценции увеличивается, при напуске воздуха интенсивность уменьшается. С каждым последующим циклом амплитуды изменений интенсивности становятся больше. Увеличения происходят симметрично за счет усиления излучения в вакууме и за счет уменьшения его на воздухе. В настоящем исследовании анализируются изменения структуры экситонной ФЛ порошка $\mathrm{ZnO}$ при сменах среды в условиях непрерывного возбуждения Не-Сd-лазером.

На рис. 2 приведены спектры ЭФЛ порошка в трех последовательных циклах смен атмосферы. Наблюдается обнаруженная ранее [3] тенденция увеличения интенсивности излучения при вакуумировании и уменьшения ее при напуске воздуха. Кроме того, обнаружено в каждом цикле смещение экситонной полосы - в длинноволновую сторону при откачке и в коротковолновую при напуске воздуха. Наблюдается рост интегральной интенсивности излучения от цикла к циклу. Несомненно, процессы фотодесорбции и фотоадсорбции, лежащие в основе полученных результатов, зависят как от исходного состояния образца, так и от интенсивности и продолжительности облучения, следствием чего может стать наблюдаемый некоторый разброс в виде кривых в разных процессе циклах воздух-вакуум. Тем не менее дальнейшие исследования позволили получить информацию об эволюции структуры экситонной полосы.

На рис. 3 представлены СФЛ порошка в двух циклах смен среды: воздух 1-вакуум 1-воздух 2-вакуум 2 Контур полосы экситонной люминесценции в исходном 

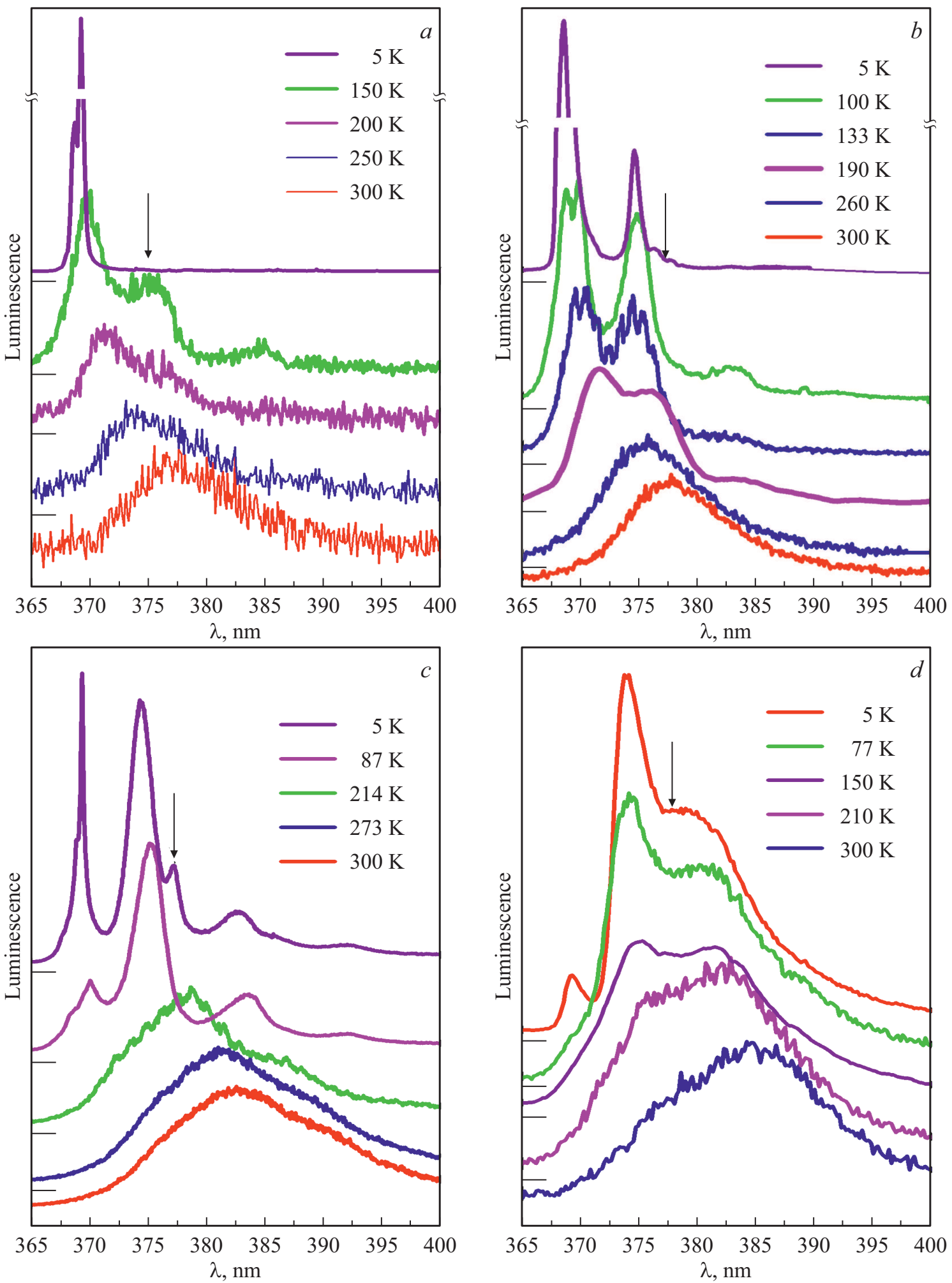

Рис. 1. Спектры ФЛ различных образцов $\mathrm{ZnO}$ при возбуждении Не-Сd-лазером в температурном диапазоне 5-300 K: $a-$ нелегированного монокристалла; $b-\mathrm{ALD}$-пленки $d=4 \mathrm{~nm} ; c-$ порошка; $d-\mathrm{ALD}$-пленки $d=450 \mathrm{~nm}$.

состоянии (кривая air 1) сложный, с максимумом при $382 \mathrm{~nm}$ и двумя отчетливыми особенностями при 376 и $391 \mathrm{~nm}$, практически повторяющий описанный выше спектр порошка при $300 \mathrm{~K}$ (рис. 1,c). В результате вакуумирования (кривая vacuum 1) наблюдается увеличение интенсивности экситонной полосы в $\sim 2.5$ раза, уширение почти в 2 раза и смещение полосы и длинноволновую сторону (максимум $-387 \mathrm{~nm}$ ), при этом 
форма полосы предполагает наличие сложной структуры. Смещение в длинноволновую сторону при вакуумировании может свидетельствовать об усилении экситон-фононной структуры. После напуска воздуха (кривая air 2) интенсивность спектра ЭЛ падает, а экситонная полоса с максимумом около $376 \mathrm{~nm}$ и слабой особенностью при $382 \mathrm{~nm}$ приобретает вид, характерный для излучения малодефектных кристаллов и пленок при $300 \mathrm{~K}$ (рис. 1). При последующем вакууме (кривая vacuum 2) наблюдаются увеличение интенсивности в $\sim 4$ раза (относительно air 2) и частичное разрешение структуры. Заметное коротковолновое смещение полосы согласуется с общей тенденцией изменения спектрального положения экситонной полосы в результате цикла (рис. 2).

Установленные ранее закономерности изменений интенсивности экситонной люминесценции при сменах среды были объяснены в [3] явлениями фотодесорбции и фотоадсорбции кислорода. Именно кислород является самым сильным окислителем из всех атмосферных газов, активно влияющим на оптические свойства. На поверхности оксида цинка молекула кислорода может находиться в слабо $\left(\mathrm{O}_{2}^{-}\right)$и сильно $\left(\mathrm{O}^{-}\right)$связанных формах [8]. В процессах фотодесорбции в первую очередь выходит слабосвязанный кислород. В результате количество дефектов в приповерхностной области образ-

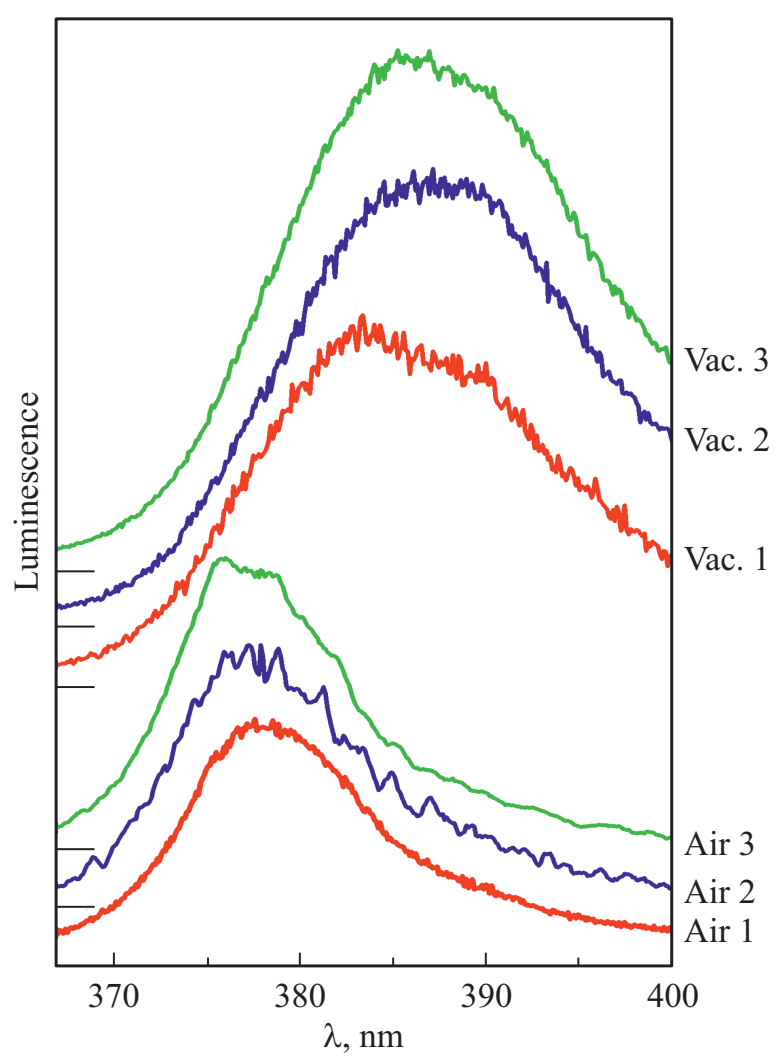

Pис. 2. Спектры ФЛ порошка $\mathrm{ZnO}$ при $T=300 \mathrm{~K}$ и непрерывном возбуждении Не-Сd-лазером в трех последовательных циклах смены среды воздух-вакуум.

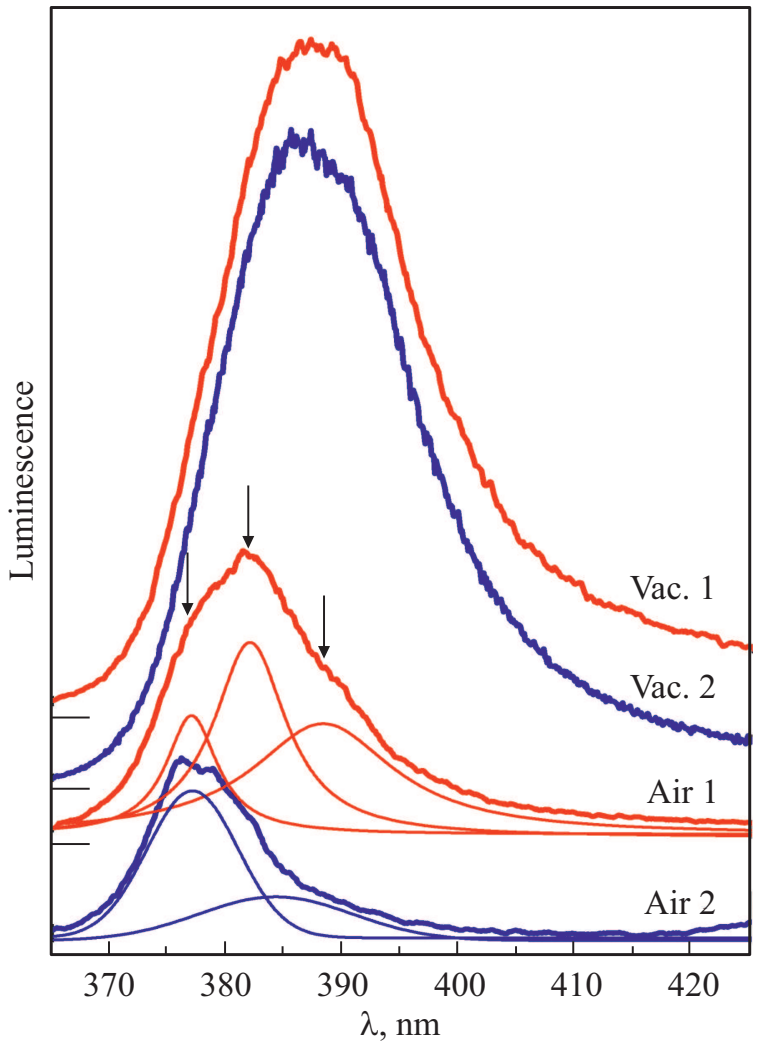

Pис. 3. Спектры ФЛ порошка $\mathrm{ZnO}$ при $T=300 \mathrm{~K}$ и непрерывном возбуждении Не-Сd-лазером в циклах смены среды: воздух 1-вакуум 1-воздух 2-вакуум 2. Для кривых air 2 и air 1 приведены разложения на 2 и 3 гауссиана соответственно.

ца возрастает. Об этом свидетельствуют и увеличение полуширины полосы излучения в вакууме, и смещение максимума полосы в длинноволновую сторону. При напуске воздуха и адсорбции кислорода количество дефектов (вакансий кислорода) уменьшается. Обратимость результатов в циклах изменения среды свидетельствует, что речь идет о собственных дефектах. Заметим, что адсорбированный на поверхности $\mathrm{ZnO}$ кислород является центром безызлучательной рекомбинации для экситонов, что также, как изменение наклона зон [3], является фактором, уменьшающим интенсивность экситонного излучения образцов на воздухе.

\section{4. Заключение}

Исследована экситонная ФЛ оксида цинка (монокристаллов, нанокристаллических порошков, тонких $(d=4$, $450 \mathrm{~nm}) \mathrm{ALD}$-пленок на $\mathrm{Si}-$-подложках в температурном интервале от 5 до $300 \mathrm{~K}$ при возбуждении $\mathrm{He}-\mathrm{Cd}$ лазером. Проанализировано формирование контура полосы экситонного излучения при $T=300 \mathrm{~K}$ образцов, спектры ФЛ которых при $T=5 \mathrm{~K}$ различаются интенсивностью полосы $374.5 \mathrm{~nm}$ (электрон зоны проводимости - акцептор). Результаты свидетельствуют, что в 
основе расхождений в положении максимума экситонной полосы излучения $\mathrm{ZnO}$ при комнатной температуре $(376-385 \mathrm{~nm})$, форме ее контура и полуширины лежат зависящие от степени дефектности образцов вклады в излучение экситонного, экситон-фононного и дефектного излучений.

Изучено влияние процессов фотодесорбции и фотоадсорбции кислорода на спектр экситонного излучения порошка $\mathrm{ZnO}$ при комнатной температуре в последовательных циклах смены среды воздух-вакуум при непрерывном возбуждении Не-Сd-лазером. Установлено влияние собственных дефектов на спектральное положение максимума, форму и полуширину экситонной полосы излучения.

\section{Благодарности}

Авторы выражают благодарность сотрудникам Ресурсного Центра СПбГУ „Инновационные технологии композитных наноматериалов“.

\section{Финансирование работы}

Работа выполнена при поддержке гранта СПбГУ № 51125686 и гранта РФФИ № 190200576.

\section{Список литературы}

[1] U. Ozgur, Ya.I. Alivov, C. Liu, A. Teke, M.A. Reshchikov, S. Dogan, V. Avrutin, S.-J. Cho, H. Morkos. J. Appl. Phys. 98, 041301 (2005).

[2] Aleksandra B. Djursis, Y.H. Leung. Small 2, 8-9, 944 (2006).

[3] И.Х. Акопян, М.Э. Лабзовская, А.А. Лисаченко, А.Ю. Серов, Н.Г. Философов. ФТТ 60, 2, 346 (2018).

[4] M. Shirra, R. Schneider, A. Reiser, G.M. Prinz, M. Feneberg, J.J. Biskupek, U. Kaiser, C.E. Krill, K. Thonke, R. Sauer. Phys. Rev. B 77, 125215 (2008).

[5] С.Ю. Вербин, С.А. Пермогоров, А.Н. Резницкий, Св.А. Пендюр, О.Я. Таленский. ФТТ 1, 84 (1989).

[6] A. Teke, U. Ozgur, S. Dogan, X. Gu, H. Morkoc, B. Nemeth, J. Nause, H.O. Everitt. Phys. Rev. B. 70, 195207 (2004).

[7] J.W. Sun, Y.M. Lu, Y.C. Liu, D.Z. Shen, Z.Z. Zhang, B. Yao, B.H. Li, J.Y. Zhang, D.X. Zhao, X.W. Fan. J. Appl. Phys. 102, 043522 (2007).

[8] V.V. Titov, A.A. Lisachenko, I.Kh. Akopyan, M.E. Labzovskaya, B.V. Novikov J. Luminescence. 195, 153 (2018).

Редактор К.В. Емцев 